\title{
Dynamic Stress Intensity Factors of Brittle Materials
}

ALBERT S. KOBAYASHI and KWAN HO YANG

University of Washington, Department of Mechanical Engineering,

Seattle, Washington 98195, USA

\section{ABSTRACT}

A new hybrid experimental-numerical procedure was used to characterize dynamic fracture A (SIF) versus (SIF) versus crack which were ob alate relations of alumina, $\mathrm{TiB}_{2}$-particulate/SiC-matrix composite and SiC Alumina-matrix composite are also presented. Available data indicated that dynamic ${ } C_{W} /$ SIF was not observed in glass and monolithic ceramics, and suggested that further

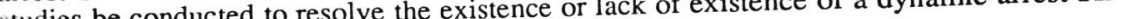
ceramic matrix composites.

\section{KEYWORDS}

Dynamic fracture testing; hybrid experimental-numerical procedure; dynamic stress intensity lass; reaction bonded silicon nitride; alumina; $\mathrm{TiB}_{2}$ factor; crack opening displacement, $\mathrm{SiC}_{\mathrm{w}}$ /alumina-matrix composite.

\section{INTRODUCTION}

Historically the destiny of dynamic fracture mechanics was set with the pioneering experimental analysis of Wells and Post (1958) augmented by Irwin's data analysis velocity (Irwin 1958). Since that time, numerous atempts have been made considered synonymous with with the apparent crack driving force which in most cases wap without proof, most of the the dynamic stress intensity factor. Hex experimental data, with the foughness was equated to the velocity versus dynamic equilibrium consideration.

Some the above mentioned Some of the colleagues experimental data wa . In particular, the dynamic stress intensity factors versus crack velocity (robions for structural ceramics, i.e. reaction bonded silicon nitride, did not exhibit a tendency for dynamic crack arrest in contrast to the familiar gamma-shaped relations which were (expents of structural metals and polym. 
lack of a dynamic crack arrest stress intensity factor, below which the running crack will arrest, in structural ceramics was particularly disturbing. From the viewpoint of fracture mechanics, the highly tou

The purpose of this paper is to review the past results on dynamic fracture testing on ceramics and to present additional experimental results which have been generated since 1986. A and to present additional experiack of a dynamic crack arrest stress intensity factor in the structural ceramics will also be presented.

\section{DYNAMIC FRACTURE TESTING OF CERAMICS}

Dynamic fracture testing of ceramics differs with that of structural metals and polymers in that the available test specimens are often as small as $6 \times 6 \times 40 \mathrm{~mm}$ bars which are dictated by the high fabrication cost and the availability of blank materials. In terms of experimental techniques, the popular optical methods for determining the dynamic stress intensity factors, such as photoelasticity and caustics, cannot be used due the titional photographic and crack ratio of ceramics. As for crack lengh musable at elevated temperature gage techniques for monitoring the rapid and at the best, inaccurate under rome impact load displacements. In addition, une applied load which must be measured outside of the furnace, coucal constraints requires the development of at the impact point on the spechievable.

The experimental procedure, which circumvented some of the above difficulties, is the hybric The experint experity is used to drive a well established dynamic finite element code (Kobayashi 1979) velocity, is used to drive a well estare will be discussed together with the experimental results in the following sections.

\section{WL-MTDCB Tests}

During the initial stage of development, the commercially available KRAK-GAGE, $25 \mathrm{~mm}$ Don rapid crack extension history during dynamic fracture at room losts were conducted with glass and locally fabricated reaction bonded silicon nitride (RBSN) specimens which permitted the luxury of using the experimentally more manageable larger wedge-lo
specimen with a side groove.

Figure 1 shows the WL-MTDCB specimens and the loading conditions used in the initial phase of this investigation. The measured crack extension and the wedge load histories were input to an implicit dynamic finite element code, which was executed in its generation mode (Kobayashi 1979), to simulate the dynamic fracture test. The work done at the smoothly released crack-tip node, which model gradual crack extension, was used to compute the dynamic stress intente compute factor of the moving crack tip. Caiib to crack extension.

The unusual specimen configuration, which was necessitated by its contemplated use at The unusual specimention. For this purpose the dynamic fracture response of 4340 steel hardened to Rockwell C44 was this purp by using the identical hybrid procedure. Four WL-MTDCB specimens with machined blunt crack tips were statically loaded to failure at room temperature. While the running cracks did not arrest in this series of dynamic fracture tests, crack arrest was observed in this inherently stiff specimen machined from annealed 4340 steel. Figure 2 shows the dynamic SIF versus crack velocity relation (Kobayashi et al. 1986) obtained in this study as well as that of Rosakis et al (1984). The agreement between the two independent results could

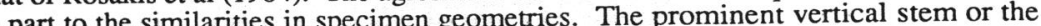
existence of a dynamic crack arrest SIF is also noted.

Figure 3 shows dynamic SIF versus crack velocity relation obtained from two plate glass WLMTDCB specimens. Also shown are the results obtained from four wedge-loaded, rectangular double cantilever beam (WL-RDCB) specimens. The crack acceleration phase, which was prominently discussed in the early study (Kobayashi et al. 1983), was later attributed to the reduced sensitivity of the KRAK-GAGE in the presence of small crack opening displacement inherent in brittle materials. Thus this initiation phase, which is an experimental artifact, has been eliminated in Fig. 3. These tests are the first of many test results which exhibited continuing crack propagation in the presence of dynamic SIF's much lower than the fracture toughness of the material.

Figure 4 shows the dynamic SIF versus crack velocity relations of two statically and six dynamically loaded, RBSN WL-MTDCB specimens. Again the crack initiation phase, which was described in a previous publication (Liaw et al. 1986), was eliminated. This figure shows that the running crack in the statically loaded specimens did not show such a trend.

\section{3-Point Bend Tests}

While the WL-MTDCB specimens used in the above investigation provided controllable crack ropagation in relatively small specimens, these specimens were too costly to fabricate in large propagation in relatively sma-point bend specimens in subsequent dynamic fracture testing wa thus dictated by the availability of specimen blanks and the relative ease in machining. Figure 5 shows the three-point bend specimens.

The KRAK-GAGE, which appeared to function well in previous room temperature fracture testing, obviously could not be used at the elevated temperature. Therefore, a noncontacting laser interferometric displacement gage (LIDG) (Sharpe 1971) was used in subsequent tests. The relative displacement between the two reflective LIDG targets is determined by the relative movements of two sets of optical interference fringes generated from a coherent light reflecte from the microhardness indentations on the targets. Fringe movements due to the changes in the relative distance between the two indentations are monitored by two photomultiplier tubes and recorded by transient recorders. Details of the LIDG rechnique as applied to fracture testing are found in (Jenkins et al 1987). In this dynamic fraD (COD) at the initial the technique was used to measure the crack opening displacement (COD) at the initial notch tip.

The loading system consisted of a drop weight tower, which is mounted integrally with a furnace, as shown in Fig. 6. The two portholes and one door, which are shielded with fused glass pane to prevent the undesirable convection air current, provictored by a load transduce outside of the furnace.

The experimental procedure consisted of relating the measure COD at the initial notch tip to the The expecimen geometry. Because of small differences in malibration curves her wo be colition which involved a combined use of the KRAK-GAGE and the LIDG techniques, the KRAK-GAGE was found to be relatively insensitive to the initial phase of crack extension in these brittle materials with small COD's. As shown in Fig. 7, the time lag and the lack of the crack acceleration phase, which was overemphasized in previous studies (Kobayashi et al. 1983: Liaw et al. 1986), in the LIDG established the limitation of the KRAK-GAGE. The 1983. Liaw et al. 196 the the calibration procedure is found in (Kobayashi et al. 1988). 
The hybrid analysis based on the above experimentally determined crack extension history The hybrid analysis based on the applied load history which had to be measured outside of the furnace. Uncertainty in the actual load applied at the load point on the specimen required the the entire loading system, which included the push rod, to be modeled in the dynamic finite element analysis as shown in Fig. 8. This complex modeling required validion which was conducted at room temperature with an additional load measurement at the impact point of the specimen (Kobayashi et al. 1988). Figure 9 shows a typical comparison between the measured and computed load. The loss of contact was established by monitoring the sign of the normal stresses of the two contacting elements in the specimen and the push rod. The aynamic finite element analysis also revealed sim
be accounted for in subsequent analyses.

The hybrid technique was then used to determine the dynamic SIF versus crack velocity relations of alumina (Kobayashi et al. 1988), TiB 2 -particulate/SiC-matrix composite and SiC whisker/alumina-matrix composite (Jenkins et al. 1988). Figure 10 shows the dynamic SIF versus crack velocity relations of four room-temperature and two $1000^{\circ} \mathrm{C}$ fracture tests of alumina three-point bend specimens. Notable is the half of the static fracture toughness.

propagation at dynamic SIF which are less than one half of the staic forami Figures 11 and 12 show the dynamic SIF versus $\mathrm{SiC}$-whisker/alumina matrix, respectively. A composites of $\mathrm{Ti}_{2}$-particulate for the low dynamic SIF region of the former is missing and more data is sought for the latter.

\section{DISCUSSION}

The unambiguous absence of the dynamic crack arrest SIF in the monolithic glass, RBSN and alumina was not obvious in the ceramic composites considered. As shown in Fig. 13, the propagating crack in a SiC-whisker/alumina-matrix, three-point bend specimen, which was

loaded under fixed grip condition, arrested at $1200^{\circ} \mathrm{C}$ (Jenkins et al 1988 ).

\section{CONCLUSIONS}

A hybid procedure for determining the dynamic SIF associated with a running crack in threeA hybrid procedure for determining the dynamic
point bend specimens at elevated temperature was established.

This procedure was used to determine the dynamic SIF versus crack velocity relations of glass, reaction bonded silicon nitride, alum

whisker/alumina-matrix composites.

Dynamic crack arrest SIF was not observed in glass and monolithic ceramics.

\section{ACKNOWLEDGEMENT}

The results reported here were generated under NASA contract NAGW-199.

\section{REFERENCES}

Wells, A.A. and D. Post, (1958). Proceedings of the Society for Experimental Stres Analysis, Vol. XVI, No. 1 69-92.
rwin, G.R.(1958), Proceedings of the Society for Experimental Stress Analysis, Vol. XVI,

No. 1 93-96.
Kobayashi, A.S., M. Ramulu, M.S. Dadkhah, K.-H. Yang and B.S.-J. Kang, (1986) International Journal of Fracture, Vol. 30 275-285.

Yed Perrone and S.N. Atluri, ASME AMD 35 19-36.

Rosakis, A.J., J. Duffy and L.B. Freund, (1984). Journal of the Mechanics and Physics of Solids, Vol 32, No. 4 443-460.

obayashi, A.S., A.F. Emery and B.M. Liaw, (1983). Fracture Mechanics of Ceramics, 6, ed. R.C. Bradt, A.G. Evans, D.P. Hasselman and F.F. Lange, Plenum

Publishing Corp. 47-61.
Liaw, B.M., A.S. Kobayashi and A.F. Emery, (1986). Fracture Mechanics: Seventeenth Volume, ASMT STP 905, ed. J.H. Underw

W.A. And N (1971). Inernation

Sharpe, Jr., W.N., (1987). American Ceramic Society Bulletin, Vol. 12, No. 66 1734-1738.

Karamic Society Bulletin, $\mathrm{K}$. Yang (1988). To be published in the Proceedings of International Conference on Advanced Measurement Techniques, British Society for Strain Measurements.

K. -H. Yang and A.F. Emery, (1988). To be published in IMPACT 87

Deutsch Gesellschaft fuer Metallkunde.
Jenkins, M.G., A.S. Kobayashi, K.W. White and R.C. Bradt, (1988). To be published in Engineering Fracture Mechanics. 


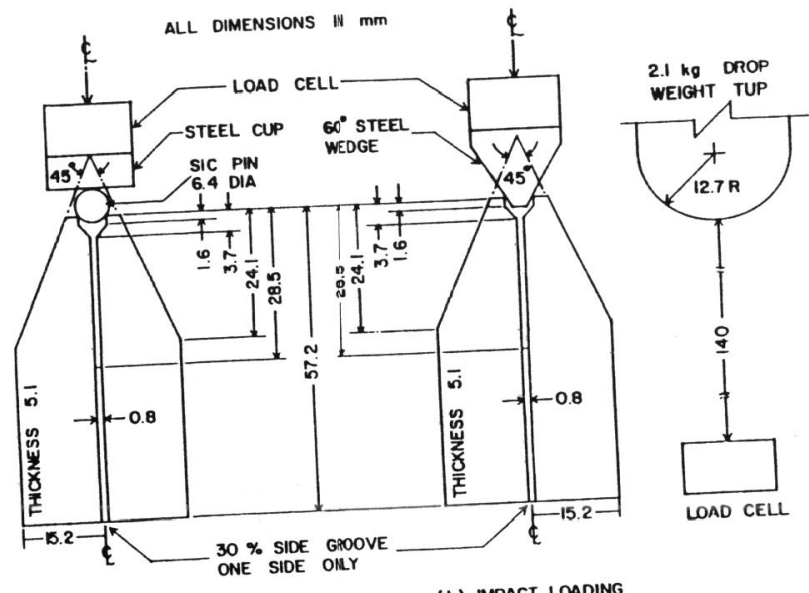

(a) Static Loadng

(b) IMPACT LOADING

Fig. 1. WL-MTDCB RBSN Specimen.

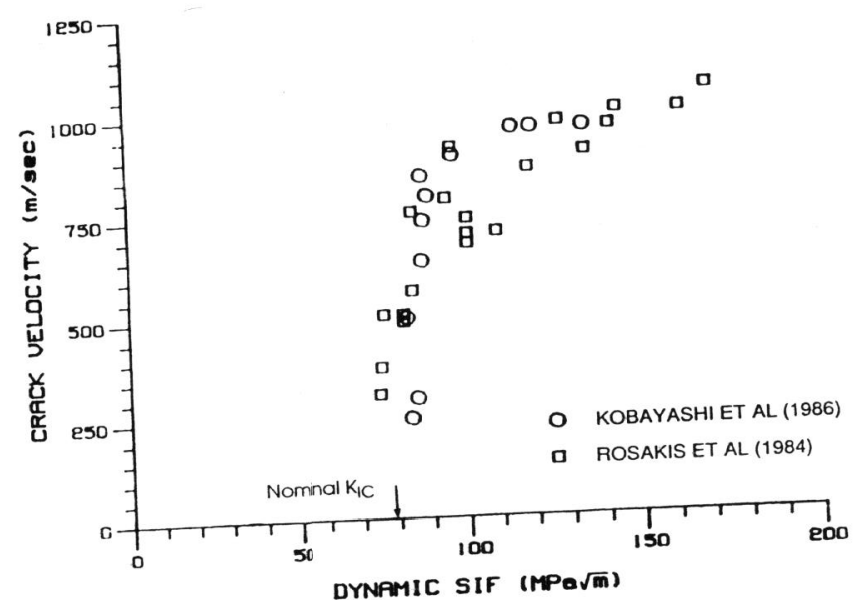

Fig. 2. Dynamic SIF Versus Crack Velocity Relation,.4340 Steel

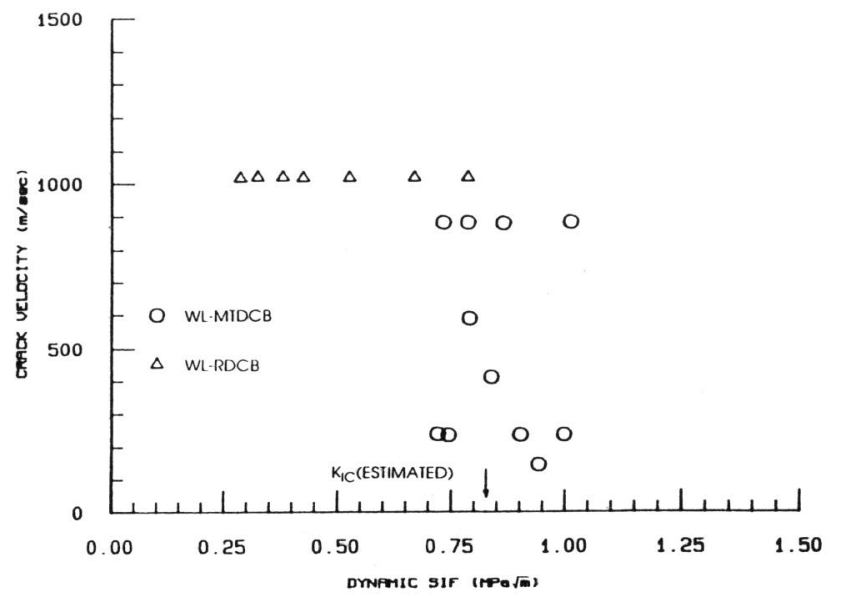

Fig. 3. Dynamic SIF Versus Crack Velocity Relation, Glass.

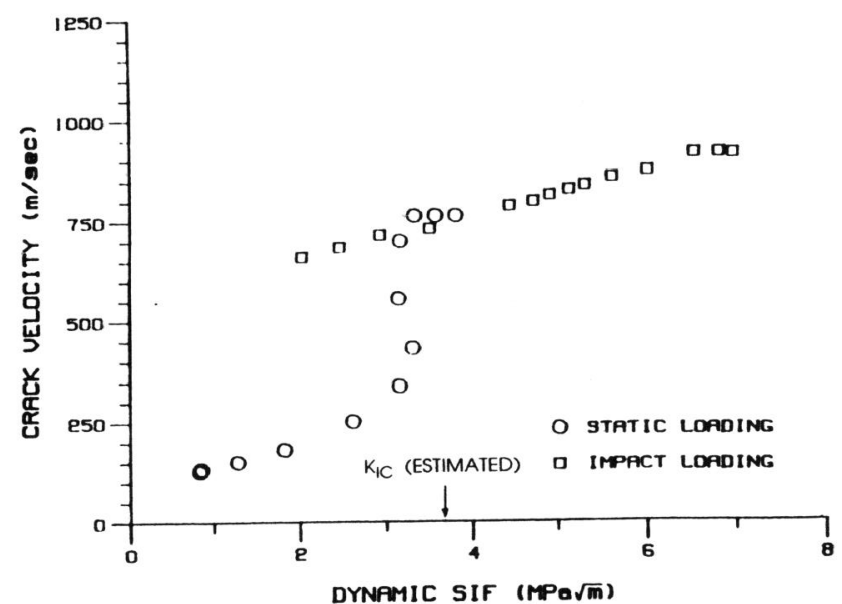

Fig. 4. Dynamic SIF Versus Crack Velocity Relation,.Blunt Notch RBSN WL-MTDCB Specimens 


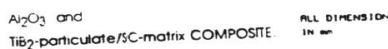
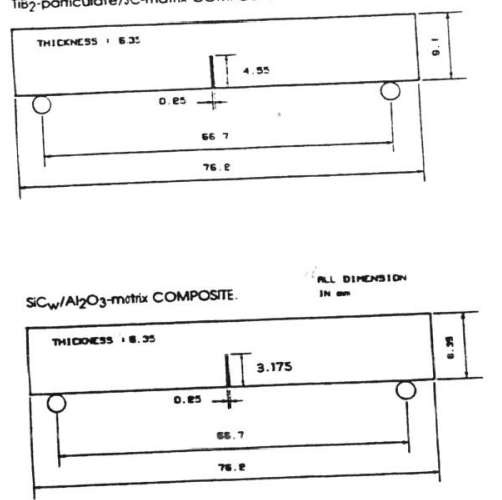

Fig. 5. 3-Point Bend Specimens.

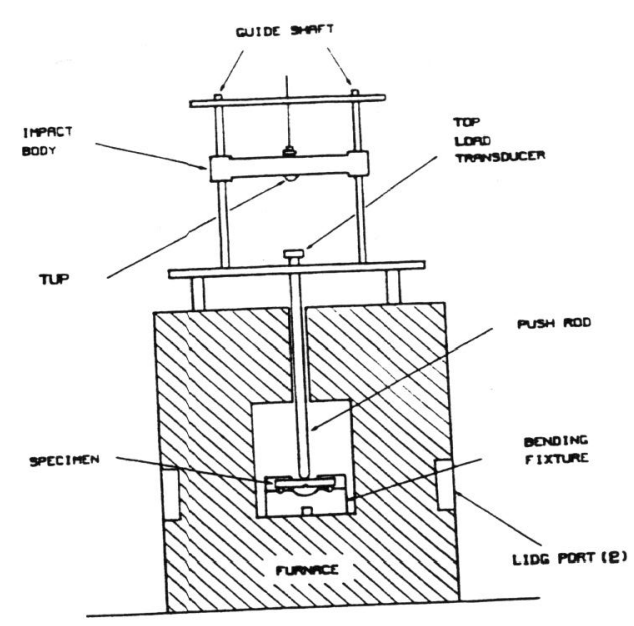

Fig. 6. Schematic Diagram of Drop-Weight Impact and Furnace with LIDG Ports.

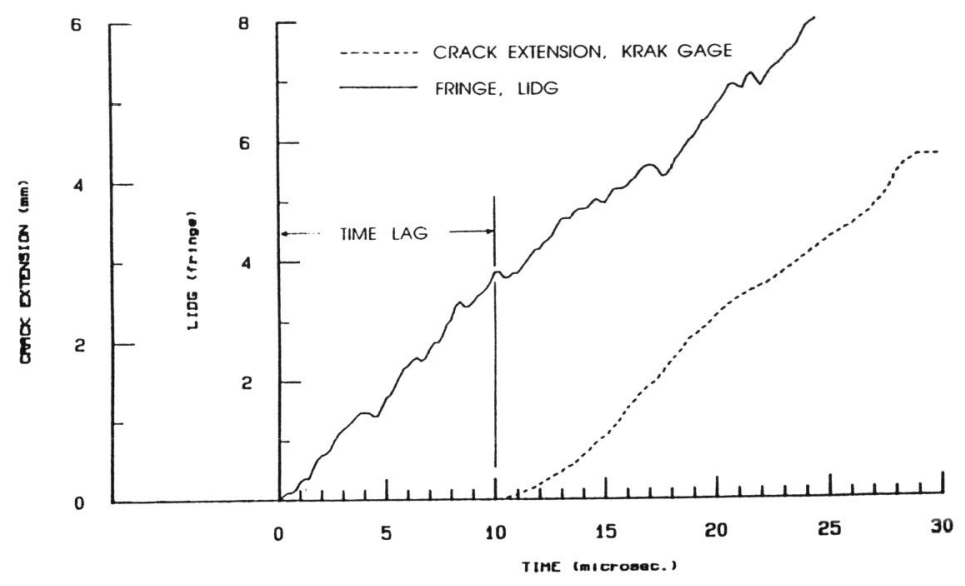

Fig. 7. LIDG Data and Crack Extension Data, TiB 2 -particulate/ SiC-matrix Composite (HE121487).

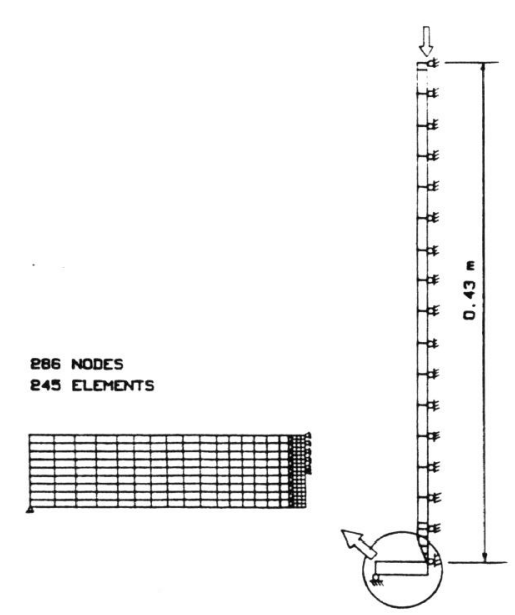

Fig. 8. Finite Element Breakdown. 


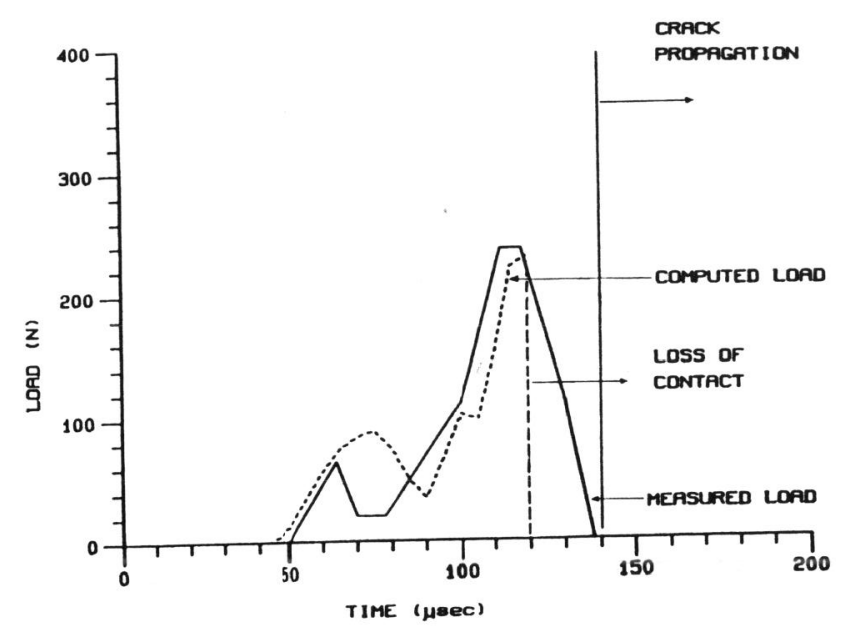

Fig. 9. Comparison of Measured and Computed Load Traces, Alumina (KH021887)..

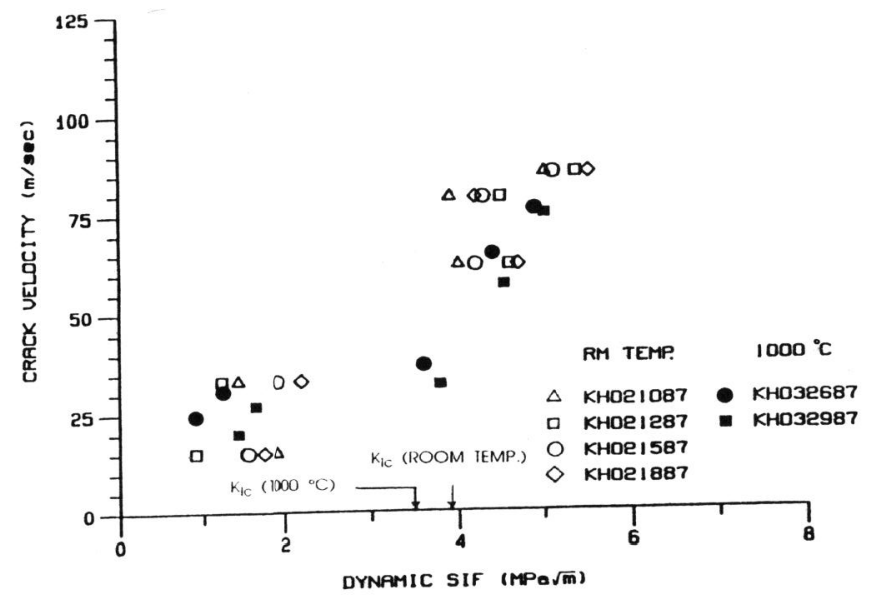

Fig. 10. Dynamic SIF Versus Crack Velocity Relation, Alumina.

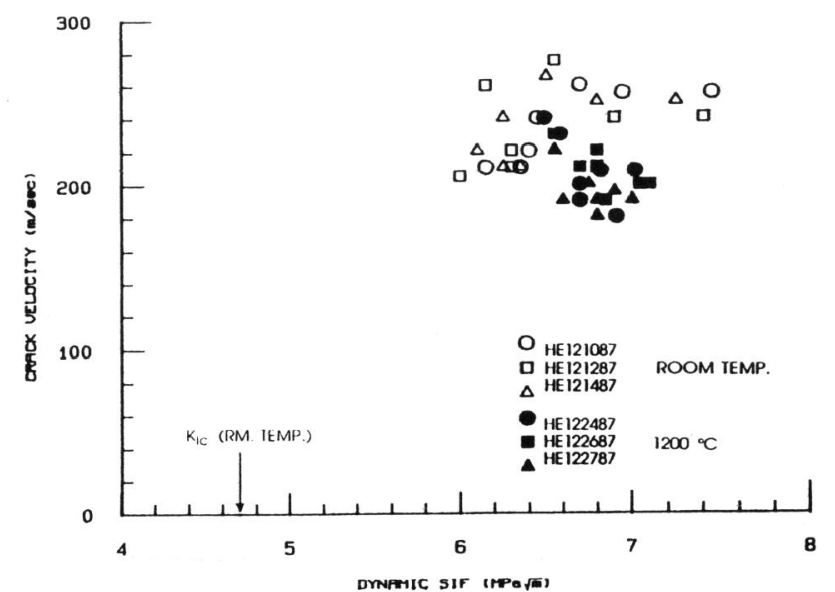

Fig. 11 Dynamic SIF Versus Crack Velocity Relation at Room and $1200^{\circ} \mathrm{C}$ Temperatures. $\mathrm{TiB}_{2}$-particulate/SiC-matrix Composite.

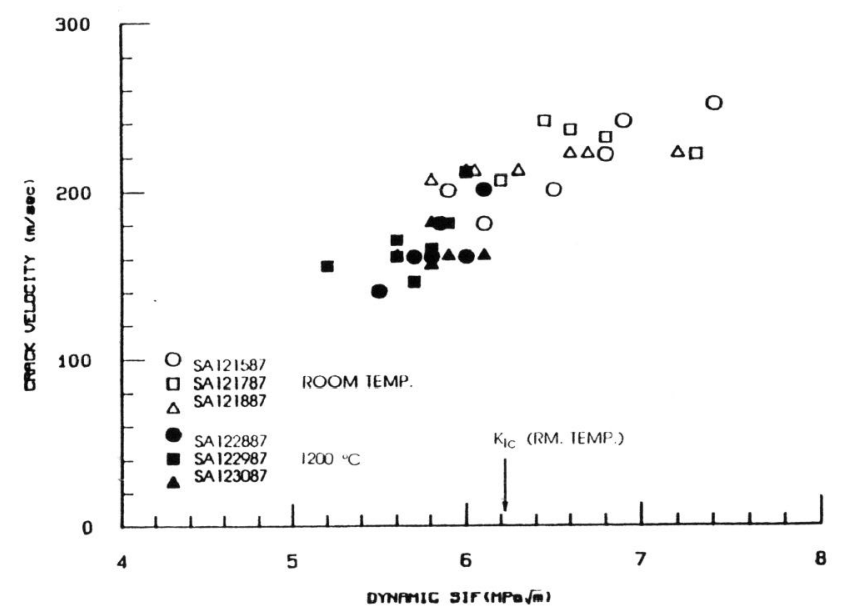

Fig. 12. Dynamic SIF Versus Crack Velocity Relation at Room and $1200^{\circ} \mathrm{C}$ Temperatures. $\mathrm{SiC}_{\mathrm{w}} / \mathrm{Al}_{2} \mathrm{O}_{3}$-matrix Composite. 


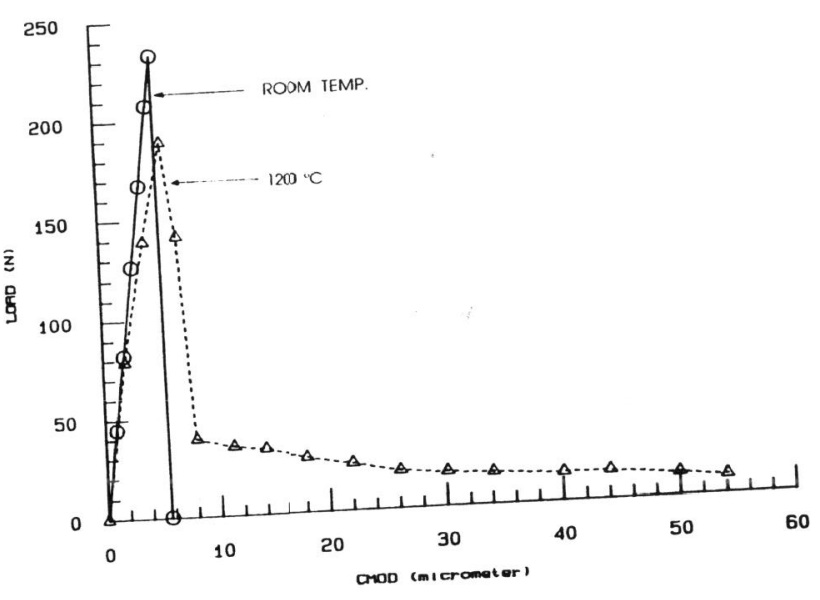
Fig. 13. Representative Load Versus Crack Mouth Opening
Displacement(CMOD) Histories for $\mathrm{SiC}$ Whisker/Al $\mathrm{A}_{2} \mathrm{O}_{3}$ Marix Composite Three-Point Bend Specimens. 